\title{
Emotional Intelligence and Social Competence: Antecedents of School Administrators' Transformational Leadership Qualities
}

\author{
Ernie C. Cerado \\ Sultan Kudarat State University, Tacurong City, Philippines \\ Samsudin N. Abdullah \\ Esperanza National High School, Esperanza, Philippines
}

\begin{abstract}
The study was carried out among administrators of big secondary schools in Region XII during the 2014-2015 school year. It centred mainly on determining the relationships of emotional intelligence (EI) and social competence (SC) of administrators on their transformational leadership qualities (TLQ). Descriptive correlational survey design was used to provide good analysis and interpretation of the results. Respondents included 15 principals and 333 teachers. The EI, SC, and TLQ mean scores of principals were collected through survey questionnaires. Means, percentages, Pearson r, t-test, and one-way analysis of variance (ANOVA) were suitably applied to describe the gathered data and make inferences as well. As found out, they have high EI, high SC, and high TLQ. Strong relationships of the principals' EI and SC to their TLQ were proven to be significant. Moreover, the principals' TLQ were affected by their educational attainment but not by the age, gender, tribe, religion, administrative experience, and civil status. Thus, the study concluded that both EI and SC of school administrators are antecedents of TLQ.
\end{abstract}

Keywords: emotional intelligence (EI), social competence (SC), transformational leadership, educational management

This study was undertaken to examine the assertion of Hebert (2011) that there is a link between transformational leadership and emotional intelligence (EI) that will ultimately result to school principals' effectiveness. Further, it will validate Saxe's (2011) theory that socio-emotional competence and transformational leadership of education leaders are significantly correlated with each other.

Likewise, this follow-up research was in response to Weinberger's (2004) suggestion that similar study will be conducted to investigate the connection between social competence (SC) and transformational leadership qualities (TLQ) among school administrators. Nonetheless, what made this new study unique and interesting was that it had big twist wherein EI and SC were intertwined with their respective indicators. Survey questionnaires that are used are based from different references to give more reliable results.

In the present study, the researcher presumed that EI and SC possessed by school administrators are related

Corresponding author: Ernie C. Cerado, Ph.D., Assistant Professor III, Colleges of Teacher Education and Graduate Studies, Sultan Kudarat State University; research fields: mathematics education, educational management, and institutional development and management. E-mail: eccphd@yahoo.com.

Samsudin N. Abdullah, Ph.D., Teacher III, Esperanza National High School, Division of Sultan Kudarat, Department of Education; research fields: mathematics education and educational management. E-mail: samsudinabdullah42@yahoo.com. 
to their own TLQ. Personal factors, however, are likewise acknowledged to have moderating effect toward transformational leadership characteristics of school heads.

\section{Objectives}

Essentially, this investigation sought to realize the following objectives, namely: (1) to describe the personal profile, and levels of EI, SC, and TLQ of the school administrators; (2) to relate EI and SC with TLQ of principals; and (3) to find out the effect of personal factors to TLQ.

\section{Methodology}

Descriptive correlational study was used in the study since it mainly focused on providing mere accounts and description of the gathered data and determining the existing relationships among variables. Respondents of 348 school administrators and teachers were randomly selected in proportionate scale from the 33 big schools (those with student-population of 1,500 and over) in the nine school divisions in Department of Education (DepEd) Region XII, namely: South Cotabato, Cotabato Province, Sarangani, Sultan Kudarat, Cotabato City, Kidapawan City, Koronadal City, Tacurong City, and General Santos City.

The modified survey questionnaires based on Likert scale were formulated to jibe with the objectives of the study. These questionnaires were composed of Secondary School Principal Questionnaires (SSPQ) or Self-Version and Secondary School Teacher Questionnaires (SSTQ) or Rater-Version. SSPQ form was administered to the secondary school principals and SSTQ form was accomplished by the secondary school teachers. The instrument has four parts, namely: Part 1 deals with the personal profile of the school administrators; Part 2 solicits information on their EI; Part 3 deals with their SC; and Part 4 deals with their TLQ of the school heads.

The EI questionnaire was adapted from Articulo and Florendo (2003); the SC survey tool was revised from the work of Han and Kemple (2006); while the TLQ tool was suitably improved from the research of Smith (2004). Other survey questionnaires were also considered for the improvement particularly on choosing the best and applicable indicators for the three main variables of the study. Validation of these instruments was done by recognized experts. On the other hand, reliability tests were made by pilot testing these tools to 20 school administrators. Generally, the respondents expressed their perception on each item of the questionnaires as Never (1), Seldom (2), Sometimes (3), Often (4), and Always (5). The instrument was properly validated by five experts and pilot-tested in one of the schools in Sultan Kudarat that resulted to a Cronbach alpha of 0.89 signifying its reliability.

Responses taken from the administrator and teacher-respondents were systematically tabulated and analysed in Microsoft Excel embedded with Q1 Macros 2014 application. Tables were used to present the summarized data. Descriptive statistics like frequencies, percentages, and means together with inferential statistical tools such as t-test, one-way analysis of variance (ANOVA), and Pearson-Product Moment Correlation were employed in analysing data in response to the objectives of the study. In particular, frequencies and percentages were used to describe the demographic profile of the respondents. Means were employed to explain the levels of the principals' EI, SC, and TLQ. The Pearson $r$ and t-test were applied to relate EI, SC to TLQ of the school heads. Both ANOVA and t-test were applied to see whether or not personal factors like age, gender, tribe, civil status, religion, educational attainment, and administrative experience have influenced the principals' TLQ. 


\section{Findings}

\section{Profile of the School Administrators}

Typically, secondary school principals among big schools in Region XII are on the retiring age of 60-64, male, married, Ilongo, and Roman Catholic. They are less than 13 years in school administration, and are doctoral degree holders. They usually serve as classroom teachers in the DepEd prior to their assumption to office as administrators.

EI

Principals' EI is described along with their ability to understand and apply self-awareness, self-regulation, motivation, empathy, and social skills in school administration. Generally, the respondents rated the principals' EI as high. This goes to show that indeed, school administrators have very satisfactory understanding of their emotions as well as their teachers. They also have very good perception on subtle social cues, read complex social situations, and demonstrate insight about others' motivations and goals.

Relative to this, Barbuto and Burbach (2006) wrote that emotionally intelligent leaders can better understand and motivate others through the use of their feelings, impulses, and sentiments. Also, Estrellan (2012) pointed out that emotionally intelligent leaders understand their people and thus help them recognize their strengths and weaknesses.

SC

This study defined SC in terms of the principals' self-management skills, interpersonal knowledge and skills, positive self-identity, cultural skill, planning and decision-making skills, and adapting social values self-management. As found out, the respondents perceived the school administrators' SC as high. This means that they are socially competent having adept and knowledgeable in handling people of diverse backgrounds.

According to Han and Kemple (2006), socially competent individuals are those who are endowed with personal knowledge and skills which are effective tools to deal proficiently with many choices, challenges, and opportunities. Wagner (2009) also cited that SC has been one of European Commission's key benchmark indicators to be targeted for prosperity and welfare of the organization. Saxe (2011) stressed that nothing happens in organizations, institutions, or business without people. Thus, dealing effectively with people of diverse backgrounds is the main concern of SC.

\section{TLQ}

In this study, these leadership qualities considered the administrator's characteristics such as compassion, feedback, achievement, commitment, performance, empowerment, communication, inspiration, and management potential. Collectively, the teachers and school administrators rated TLQ as high. The result suggests that principals are transformational leaders who are able to motivate, inspire, and persuade teachers to be good followers and soon become leaders who will be able to create valuable and positive change in the organization.

Judge and Piccolo's (2004) study confirms that sound transformational leadership competence of school administrators does not only enhance learning outcomes, but it yields successful schools owing to a clear sense of direction. Along this line, Smith (2004) theorized that leaders with vision and passion can reach great achievements.

\section{EI, SC, and TLQ of School Principals}

Analyses in Table 1 show that EI and TLQ of school principals are related to each other. This connotes that 
the higher EI do principals have, the better they are in TLQ.

SC was also found to be related to the TLQ. This means that if they are socially competent, they have most likely better in transformational leadership manners. When both EI and SC were simultaneously correlated to TLQ, it was found to be very strong and significant. This proved that EI and SC of principals are remarkably linked to their TLQ.

Table 1

Correlational Analysis of EI, SC, and TLQ

\begin{tabular}{lll}
\hline Variables & $\mathrm{r}$ & $\mathrm{t}$ \\
\hline EI and TLQ & 0.88 & $34.46^{*}$ \\
SC and TLQ & 0.91 & $40.83^{*}$ \\
EI, SC, and TLQ & 0.92 & $43.66^{*}$ \\
\hline
\end{tabular}

Notes. $\mathrm{t}_{\text {crit }(0.05,2 \text {-talied })}=1.97 ;^{*}$ - significant.

Apparently, the finding confirms Hebert's (2011) view that transformational leadership competence is dependent largely on the ability to handle people and social interactions. In other words, school principals cannot be considered as transformational leaders unless they are competent in dealing with people of diverse backgrounds, needs, and priorities. It also validated the theory of Saxe's (2011) theory that socio-emotional competence and transformational leadership of education leaders are correlated with each other.

\section{TLQ and the Principals' Personal Factors}

As found out, the TLQ of school principals are not affected by their age, tribe, religion, and administrative experience. Educational attainment, however, affects it as indicated by F-ratios shown in Table 2.

This signifies that transformational leadership characteristics of administrators are not fully influenced by personal factors. Fortunately, the principal's educational level matters. Most probably, the likelihood is extraordinary because educators might have developed awareness in attending formal studies from graduate schools or management programs where they tend to assimilate new leadership qualities.

Table 2

ANOVA on the TLQ of Secondary School Principals When Grouped by Age, Tribe, Religion, Administrative Experience, and Educational Attainment $(n=15)$

\begin{tabular}{lll}
\hline Personal factors & F-ratio & $\mathrm{F}_{\text {crit(0.05) }}$ \\
\hline Age & 1.20 & 3.48 \\
Tribe & 1.33 & 3.48 \\
Religion & 0.92 & 3.59 \\
Administrative experience & 0.78 & 3.48 \\
Educational attainment & $17.85^{*}$ & 3.89 \\
\hline
\end{tabular}

Note. ${ }^{*}$ - significant.

\section{Conclusions and Recommendations}

The foregoing findings lead to a conclusion that both EI and SC are indeed antecedents of school administrators' TLQ. Similarly, educational attainment influences one's leadership behavior but not the other personal factors like age, religion, administrative experience, and tribe.

Knowing that these variables are interrelated, school administrators should be aware and highly informed 
about it. Thus, a seminar-workshop for the purpose may be undertaken at the division level, or an orientation at the district and school levels might work for creative district and school heads. As part of the activities, they may assess themselves first to determine the condition of their EI, SC, and TLQ. With these, they may find ways and means to enhance them to a very satisfactory level.

Not only that, this awareness effort on EI and SC may also be effective to aspiring principals because they could benefit much from understanding the critical role that these variables play in one's leadership qualities. Hence, it might be reasonable to recommend that the existing National Qualifying Examination for School Heads (NQUESH) be revisited and reviewed to possibly include assessments of EI and SC of the candidates.

It is also practical for DepEd to uphold one's educational attainment as prime requisite in recruiting, selecting, and promoting someone as school administrator.

\section{References}

Articulo, A. C., \& Florendo, G. G. (2003). Values and work ethics. Bulacan, Philippines: Trinitas Publishing, Inc.

Barbuto, J. E., \& Burbach, M. E. (2006). The emotional intelligence of transformational leaders: A field study of elected officials. The Journal of Social Psychology, 146(1), 51-64.

Clarke, N. (2010). Emotional intelligence and its relationship to transformational leadership and key project manager competencies. Project Manager Journal, 41(2), 5-20.

Estrellan, J. C. (2012). Emotional intelligence and leadership behaviour of secondary principals in the Division of Sultan Kudarat. Unpublished master's thesis. Sultan Kudarat State University (SKSU), ACCESS Campus, EJC Montilla, Tacurong City, Sultan Kudarat.

Fagan, T. (2011). ECE Online: Social competence, interactions, behaviour and friendship. Retrieved from http://eceonline. core-ed.org

Han, S., \& Kemple, K. (2006). Components of social competence and strategies of support: Considering what and how to teach. Early Childhood Education Journal, 34(3), 241-246.

Hebert, E. B. (2011). The relationship between emotional intelligence, transformational leadership, and effectiveness of school principals. Published dissertation. Department of Educational Policy Studies, Georgia State University, Atlanta, Georgia.

Judge, T. A., \& Piccolo, R. F. (2004). Transformational and transactional leadership: A meta-analytic test of their relative validity. Journal of Applied Psychology, 89(5), 755-768.

Nash, W. (2010). Transformational school leadership and student achievement: A case study. Southeastern Teacher Education Journal, 3(1), 55-66.

Saxe, D. (2011). The relationship between transformational leadership and the emotional and social competence of the school leader. A dissertation submitted to the Faculty of the College of Education, Chicago, Illinois, USA.

Smith, J. (2004). The transformational leadership questionnaire (TLQ) survey form. Retrieved from http://www.researchgate.net

Smith, P., \& Bell, L. (2011). Transactional and transformational leadership in schools in challenging circumstances: A policy paradox. Management in Education, 25(2), 58-61.

Wagner, G. (Ed.). (2009). RatSWD working paper series. Berlin: Council for Social and Economic Data.

Weinberger, L. A. (2004). An examination of the relationship between emotional intelligence, leadership style and perceived leadership effectiveness. Saint Paul, M.N.: Human Resource Development Research Center.

White, R. P. (2004). The future of leadership: Riding the corporate rapids into the 21st century. New York: Philip Hodgson \& Stuart Crainer. 